\title{
Aplicación de un Sistema de Información Geográfica (SIG) para cartografiar redes ferroviarias. Propuesta metodológica
}

María Alejandra Saus

CONICET / Instituto de Humanidades y Ciencias Sociales del Litoral, Universidad Nacional del Litoral, Argentina.

https://orcid.org/oooo-0003-2112-710X

\section{Julián Rolé}

Facultad de Humanidades y Ciencias, Universidad Nacional del Litoral, Argentina. https://orcid.org/oooo-0002-5478-8812

\author{
Andrés Ignacio Aguirre \\ Facultad de Humanidades y Ciencias, Universidad Nacional del Litoral, Argentina. \\ https://orcid.org/0ooo-0002-3200-6488
}

Recibido: 9 de octubre de 2019. Aceptado: 28 de noviembre de 2019.

\begin{abstract}
Resumen
La interoperabilidad de un sistema de información unificado desafía el manejo de datos y su comunicación en un mismo formato. El ferrocarril argentino transita un momento de modernización, por lo cual es esencial disponer de un conjunto de datos precisos sobre su red. La variedad y dispersión de fuentes amerita el desarrollo de un criterio objetivo sobre la recolección de esa información. Por ello, el uso de los SIG se presenta como una herramienta adecuada para acompañar tal proceso, brindando grandes ventajas a la planificación. Este artículo propone una metodología para el manejo de la información y concluye sobre la pertinencia de homologar y establecer un criterio unificador de los datos al diseñar un SIG. El trabajo se compone de dos secciones: una de ellas trata sobre las fuentes sustanciales para un trabajo con SIG sobre ferrocarriles y la otra presenta el modelo de acción propuesto por los autores.
\end{abstract}

Palabras clave: Infraestructura ferroviaria. Sistemas de Información Geográfica. Metodología. Normalización. 


\title{
Application of a Geographic Information System (GIS) for mapping railway networks. Methodological proposal
}

\begin{abstract}
The interoperability of a unified information system challenges data management and communication in the same format. The Argentinian railway is going through a moment of modernization, which is why it is essential to have a set of precise data about its network. The diversity of sources merits the development of an objective criteria on the collection of that information. Thus, the use of GIS is presented as a suitable tool to accompany this process, providing great advantages for planning. This article proposes a methodology for information management and concludes with the pertinence of homologating and establishing a unifying criterion of data when designing a GIS design. The work consists of two sections: one of them is focused on the substantial sources for working with railways GIS and the other presents the model proposed by the authors.
\end{abstract}

Keywords: Railway infrastructure. Geographic Information System. Methodology. Normalization. Palavras-chave: Infraestrutura ferroviária. Sistema de Informação Geográfica. Metodologia. Normalização.

\section{Introducción}

Con la implementación de políticas neoliberales en la década de 1990 los ferrocarriles profundizaron su situación de deterioro en América Latina, llegando a condiciones paupérrimas en el estado de su infraestructura y servicios. No obstante, en la Argentina, tras las privatizaciones y la descentralización sufridas y la gran crisis atravesada en el año 2001, se "adopta un nuevo esquema de crecimiento que, desde lo macro impulsa una estrategia agroexportadora sustentada en un tipo de cambio alto en un ambiente internacional donde la coyuntura se caracteriza por precios favorables" (Raposo, 2013:3). En el panorama de esa recuperación económica, las miradas fueron puestas en revertir la situación descrita para los ferrocarriles de carga. Recientemente, tal como marca Schweitzer (2013), una serie de políticas públicas y proyectos han sido formulados e implementados, tanto desde la escala nacional como de organismos supranacionales, para aprovechar la disponibilidad de financiamiento y de inversiones. Uno de estos casos son los proyectos de UNASUR que dentro de sus ejes de integración en el COSIPLAN, específicamente el Eje Capricornio, intenta promover el desarrollo vinculado y coordinado de transporte, energía y comunicación. Se destaca el énfasis puesto en la rehabilitación y modernización del sistema ferroviario.

En la escala nacional se destacan actualmente una serie de iniciativas, dentro de las cuales, se distingue Unidad Plan Belgrano cuyos fines son reactivar ramales que han quedado en la obsolescencia luego de las políticas privatizadoras de la década de los '90. La puesta en marcha se está realizando en sectores estratégicos buscando una mejor funcionalidad y eficacia en el transporte ferroviario con el fin de trasladar producciones fundamentalmente primarias hacia los puertos para su posterior exportación.

En los últimos años la gestión pública ha materializado estas iniciativas al rehabilitar parcialmente algunos servicios de pasajeros y cargas. El énfasis discursivo del Estado y de las empresas privadas intervinientes se ha puesto en el objetivo de trasladar cargas para lograr un avance de las economías regionales del norte y noroeste argentino. No obstante, han emergido críticas a ese proyecto, sobre todo en lo que respecta a la efectiva reactivación de las economías regionales, esgrimiendo la hipótesis de que los planes nacionales y supranacionales no plantearían un desarrollo territorial equitativo (Rascovan, 2016). 
Partiendo de esa coyuntura de recuperación de los ferrocarriles argentinos y tras haber detectado una notable dispersión de las fuentes de información sobre los trazados ferroviarios, hallamos un nicho propicio para indagar sobre las redes ferroviarias y el estado de conservación de las vías del Ferrocarril Belgrano. Ello nos llevó al objetivo de confeccionar una cartografía ferroviaria unificada con el uso de programas SIG. Pero en ese proceso de investigación detectamos numerosas dificultades que han motivado la redacción de este artículo como un compendio de sugerencias metodológicas para la construcción de nuevos mapas. Las limitaciones señaladas refieren, principalmente, a la escasez de producciones sobre el tema, la desorganización de la información, la falta de criterios unitarios, la heterogeneidad de los datos obtenidos, entre otras.

Precisamente, nuestra propuesta está dirigida al diseño de una metodología particular para aplicar al uso de un SIG orientado al cartografiado de infraestructura ferroviaria en la Argentina. Este abordaje permite el entendimiento global de la situación ferroviaria en nuestro país, de acuerdo a las políticas que llevan a cabo los gobiernos nacionales, pero también nos hemos adentrado en los efectos que ellas producen en el territorio particular y específico de la ciudad de Santa Fe. Como menciona Buzai (2013), el SIG es una tecnología informática que facilita la obtención, almacenamiento, tratamiento y reporte de datos espaciales para el apoyo en la toma de decisiones territoriales. A causa de ello, y en un contexto donde "cada vez son más frecuentes los inventarios sobre redes de carreteras y ferrocarriles basados en tecnologías SIG" (Gutiérrez Puebla y Gould, 1994:229), vemos la necesidad de abordar esa temática y reflejar las dificultades y los beneficios de la herramienta para la representación de infraestructuras ferroviarias.

En el caso particular de la República Argentina, la creación y mantenimiento de algún inventario referido a la temática ferroviaria -desde diversos entes en cualquiera de las escalas jurisdiccionales- remite a formatos vectoriales, visores y serie de tablas que nombran y ubican en el espacio los elementos referidos a ese modo de transporte. Pero en cuanto a la actualización de dichos datos, la precisión y la posibilidad de compartirlos, se observan importantes falencias. Es decir, no hay articulación en el procesamiento de los datos para la posterior generación de información ferroviaria. Si bien el Consejo Suramericano de Infraestructura y Planeamiento (COSIPLAN) perteneciente a la Unión de Naciones Suramericanas (UNASUR), se ha dedicado a integrar información referida a los transportes creando un sistema para visualizar los recorridos y sus características, éste sólo funciona como un visor ofrecido por el sitio oficial. De tal manera, se detectan una serie de "problemas cartográficos" como expresan Amores et al., (1996), que se verifican en cierta medida en nuestro país.

Destacamos la función que cumple la Infraestructura de Datos Espaciales de la República Argentina (IDERA) como comunidad de información. Pretende facilitar el manejo de la información geoespacial de forma homologada y descentralizada que contribuya a garantizar la interoperabilidad y calidad de la información generada en el ámbito nacional. Para ello integra una variedad de Infraestructura de Datos Espaciales (IDE) que, a través de un catálogo elaborado, sistematiza diferentes elementos geográficos. De esta forma, dentro de la clase "Transporte" se ubica la subclase "Ferroviario" definida como "objetos geográficos que se refieren al transporte sobre rieles" (Catálogo de IDERA, 2019). La misma se compone de tres objetos, "ferrocarril", "estación ferroviaria" y "playa ferroviaria". IDERA concentra en el primer objeto tanto a ferrocarriles, subterráneos, tranvías, entre otros. En lo que refiere a la estación y playa ferroviaria, la institución hace la distinción pertinente a cada una.

Cada objeto cuenta con sus atributos donde se detallan nombres geográficos, términos genéricos y específicos, y el estado de las infraestructuras. En este sentido afirmamos la importancia de la estructura de la IDE a la hora de su utilización en estudios sobre la organización y planificación territorial. Al existir una variedad de entidades que 
realizan aportes a la conformación de esta fuente, IDERA se torna un espacio necesario para investigar y estandarizar la información para futuros proyectos de investigación, principalmente por la precisión y detalle dentro de cada una de las categorías.

Por todo lo expuesto, sugerimos un camino para llegar a resultados satisfactorios en la manipulación del software y de la información ferroviaria. Procuramos compartir un posible know how multidisciplinario para la resolución de problemáticas espaciales ferroviarias haciendo uso de las herramientas SIG. Para ello partimos de la base que es una tecnología basada en almacenar, manejar y explotar datos espaciales (es decir, geográficos) en forma digital. Este es uno de los objetivos del trabajo de recopilación y unificación de los datos dispersos y elaborados. El sistema está formado por subsistemas utilizados para capturar, analizar, visualizar y graficar dichos datos espaciales georreferenciados, favoreciendo el posterior análisis de problemáticas existentes en torno al trazado de las vías férreas. Lejía Luna (2010) sostiene que su característica fundamental es el manejo de datos geométricos (coordenadas e información topológica) y datos de atributos (información nominal) la cual describe las propiedades de las entidades geométricas propias del software: puntos, líneas y polígonos. Claramente, las líneas serán las geometrías predominantes en el modelo, representando en nuestro caso a las trazas ferroviarias.

Frente a la gran cantidad de definiciones que existen sobre los SIG, tomamos como base la de Sastre (2010) quien los define como la integración organizada de recursos humanos, hardware, software y datos geográficos. Éstos han sido diseñados a fin de obtener información geográficamente referenciada de gran utilidad para resolver problemas complejos de planificación y gestión. Por lo tanto, afirmamos que las potencialidades de estos sistemas en el tratamiento de la información ferroviaria abarcan tanto su cartografía, como la posibilidad de relacionar información geográfica con otra descriptiva dada su naturaleza integradora. Asimismo, es un instrumento esencial y eficiente para problematizar y resolver deficiencias en cuanto al medio de transporte, ya que es posible digitalizar los trazados en toda su extensión, clasificando cada una de las líneas según sean las variables seleccionadas. En este sentido, se puede unificar un conjunto de datos e información dispersa en un solo proyecto para luego crear cartografías sobre la infraestructura ferroviaria a partir de su estado.

El trabajo sobre los ferrocarriles a partir del uso de SIG ha sido desarrollado por algunos autores locales, aunque pocos han logrado un abordaje integral sobre la red ferroviaria argentina. Existen artículos que plasman ideas trabajadas en otros países, en contextos políticos, sociales y económicos disímiles al nuestro. Gómez Castaño (2013) ha puesto el foco en las cuestiones de ubicación y circulación del medio de transporte en España, analizando y mejorando su funcionalidad a través de los softwares geoespaciales. La propuesta del autor ha sido agilizar y proporcionar resultados, denotando la necesidad de utilizar los SIG para optimizar recorridos, detectar zonas de influencia ferroviaria, de trabajo, o la capacidad de la infraestructura. Su metodología bien podría ser aplicada a nuestro caso de estudio, utilizando ese valioso enfoque como herramienta de gestión, señalando falencias y deficiencias del sistema ferroviario.

Castaño (2012) toma una escala mayor y propone un modelo para todo el continente europeo con el fin de aportar una alternativa a los organismos de transporte y empresas ferroviarias pertinentes a dicho territorio, fundando sus aportes en la interoperabilidad. Su trabajo ha sido acompañado de las ideas del Instituto Geográfico Nacional español, pero manifiesta una insuficiente cantidad de aplicaciones geoespaciales sobre la temática de los ferrocarriles, por lo que insiste en la necesidad de su desarrollo. La situación es similar a la que atraviesa nuestro país, por lo que estas investigaciones enriquecen al transporte ferroviario aportando una nueva mirada, sobre todo desde la utilización de esta valiosa tecnología en constante demanda por parte de los organismos encargados 
de la gestión pública. La construcción de una infraestructura de datos espaciales sobre este medio es un nicho que debe ser profundizado.

En nuestro país y en un proyecto de ingeniería, Campolesi y Paloma (2010) han desarrollado un análisis de la evolución de la ciudad de Rosario entorno al fenómeno ferroviario y bajo el estudio de los SIG. Su objetivo principal ha sido la elaboración de un sistema que permita visualizar el impacto generado por las redes ferroviarias en esa área metropolitana. Las autoras han dado una perspectiva histórica al uso de estas herramientas, sumando la infraestructura en distintos momentos históricos. Si bien ese escrito es un gran aporte por la visión que las autoras otorgan al SIG vinculándolo a la infraestructura de trenes -exponiendo las ventajas del software frente a los de diseños CAD- creemos que, en lo referente a la utilización del programa, sólo se limitan a demostrar un paso a paso, exponiendo cuestiones básicas del mismo.

El texto de Bonfanti, Cardozo y Parras (2006) también se centra en un espacio local como lo es la ciudad de Resistencia en la provincia de Chaco, estudiando el transporte público en general. Para el armado del SIG han hecho uso de bases de datos extraídas de sitios webs de organismos públicos y privados y digitalizaciones de planos. En sus estudios intentan mostrar la dependencia de los servicios con respecto al centro neurálgico de la ciudad y la situación contraria hacia la periferia. Es interesante ver aquí cómo los medios de transporte son un nexo entre la población resistenciana y su relación con la densidad. Esas conclusiones, elaboradas a través del análisis geoespacial del movimiento de pasajeros, parecen ser extrapolables al tráfico de cargas donde el Ferrocarril Belgrano es uno de los interconectores entre los centros productores de materias primas y los puertos de exportación. Así los SIG muestran cómo los intereses sectoriales direccionan y dan valor a ciertos espacios de manera selectiva.

El artículo describe, primero, las fuentes más relevantes para obtener información espacial sobre los ferrocarriles en la Argentina y luego explica la propuesta metodológica, mostrando el procedimiento de normalización y sistematización de esa información en distintos apartados. Ese procedimiento es resultado de dos trabajos de investigación: uno referido a la red del Ferrocarril Belgrano, a escala nacional, y el otro al Área Metropolitana de Santa Fe.

\section{Fuentes de información sobre redes ferroviarias argentinas}

Una de las características que tiene la producción de un SIG es precisamente el manejo, disponibilidad y fácil adquisición de la información, siendo ésta el insumo principal, aunque muchas veces resulta ser un problema, ya sea por la escasez o no disponibilidad de fuentes, como la desorganización e incoherencias en cuanto a los datos hallados. A partir de ello, algunos autores postulan diversos métodos como Castellanos-Barrero (2010) que propone tres metodologías. La primera está basada en la percepción remota o teledetección que surge de la obtención de información acerca de una superficie por medio del análisis automatizado de datos obtenidos a distancia. La segunda implica la digitalización de información planimétrica, método al cual se suma Solanas-Jiménez (2018). Este es un método útil ya que permite localizar información temática de una cartografía, aunque implica mucho tiempo ya que es una tarea artesanal. La tercera forma compartida es la construcción de bases de datos a partir de fuentes confiables que pueden ser transformadas a condiciones espaciales y analizadas en un contexto territorial definido. Solanas-Jiménez suma dos alternativas más: la georreferenciación como forma básica para introducir planos y mapas en un SIG y la transcripción basada en la identificación de elementos representados manualmente. En el primer caso, se trata de la asociación de varios puntos de control de una imagen digital con coordenadas 
conocidas, el segundo utiliza fuentes de una cartografía antigua a partir de la cual el investigador diseña el mapa.

Ahora bien, en el desarrollo de nuestro trabajo, dentro de los objetivos planteados en la investigación, abordamos la cuestión ferroviaria argentina en los últimos años a partir del proceso de modernización de sectores de la red. Por lo tanto, la metodología seleccionada estuvo relacionada a la digitalización, corrección y actualización de geometrías, y a la búsqueda de bases de datos en distintas fuentes. Se ha optado por este procedimiento por diversas razones. Por una parte, como ya hemos mencionado, porque existe una cantera de información amplia sobre la infraestructura ferroviaria que ha sido tomada como punto de partida. Además, algunas de ellas ofrecen archivos para su visualización digital. En consecuencia, se ha tomado esa información como un corpus sobre la infraestructura ferroviaria, del cual partimos para trabajar en su actualización tanto en corrección atributiva o de características topológicas o digitales.

Es por ello que hemos decidido compartir los distintos sitios y bibliografías utilizadas que pueden servir de orientación en la construcción de trabajos futuros. De modo genérico y como primer acercamiento, Mapcruzin es una página británica de firma independiente que se especializa en proyectos de SIG, investigación ambiental y sociodemográfica, pudiendo utilizarse capas vectoriales de las redes férreas de distintos países y discriminar el estado operativo de los ramales. Pero son evidentes las dificultades y falta de exactitud en la precisión y en los datos. La tabla de atributos se muestra muy incompleta y no tiene demasiado rigor para su utilización en una investigación científica. También es posible utilizar Open Street Maps y Geofabrik que muestra similitudes en cuanto a la información ya que trabaja con los mismos datos. Ambos son mapas online creados por una comunidad de usuarios de fácil acceso para modificar lo compartido.

A escala continental destacamos como fuente primaria a la Unión de Naciones Suramericanas (UNASUR) que agrupa a diversos estados latinoamericanos y tiene como objetivo primordial el fortalecimiento del diálogo entre sus miembros para asegurar un espacio de concertación y reforzar la integración suramericana. UNASUR ha creado un SIG donde puede visualizarse a los países de la Unión y sus respectivos proyectos de infraestructura. Además, comparten informes como el de "Insumos para elaborar una estrategia que facilite la integración Ferroviaria de Suramérica”, donde se muestran cuestiones referidas al sistema ferroviario de los países miembros y sus planes.

Dentro de los límites del territorio argentino hallamos varios entes. La Comisión Nacional de Regulación del Transporte (CNRT) forma parte de la estructura del Ministerio de Transporte de la Nación. Ésta provee informes estadísticos sobre el sistema ferroviario, sumado a un mapa de la red nacional -similar a Trenes Argentinos Cargas- actualmente bajo la administración de aquel mismo Ministerio. Asimismo, la red de cargas engloba tres líneas diferentes: Belgrano, San Martín y Urquiza. El sitio provee información sobre normativas, licitaciones, proyectos e inversiones y cartografías del trazado. Distingue aquellos que están en operación, circulación eventual y sin circulación, siendo información muy importante para avanzar en investigaciones como la nuestra. Otra ventaja que tiene es la definición de los detalles de las grandes ciudades que, debido a la escala, no pueden notarse en un mapa de la red férrea. Asimismo, en el sitio de Trenes Argentinos Operaciones es posible hallar información de la misma índole.

Por otro lado, el Instituto Geográfico Nacional (IGN) permite el acceso a múltiples archivos shapefile, que están en continua actualización (límites políticos-administrativos, plantas urbanas, infraestructura de transporte, redes ferroviarias discriminadas por líneas). Los que refieren a la capa "red ferroviaria" (líneas), actualizada en marzo de 2016, muestran algunas imprecisiones, por ejemplo, todos los ramales figuran en estado "activo", aunque sabemos que gran parte de la red nacional se encuentra en 
estado de inoperatividad y abandono. Sumado a ello, las trazas no tienen un correcto nivel de precisión, cuestión evidente al superponer una imagen satelital o al comparar con otros shapefiles sobre la misma temática, como la del Ministerio de Obras Públicas y Viviendas (MIOPV) que, además, reúne gran cantidad de elementos geoespaciales.

Satélite Ferroviario se presenta como "un espacio independiente promovido por viajeros y amantes del ferrocarril". El sitio no depende de ninguna empresa, gremio o entidad ferroviaria y está armado artesanalmente con datos provenientes de distintas fuentes, aunque en gran parte gracias a las colaboraciones de los diferentes pasajeros. Su objetivo es promover y defender el tren de larga distancia y el modo ferroviario en general. La página web ofrece una cartografía nacional donde se detallan los ramales activos o con algún tipo de actividad eventual, diferenciando los servicios de carga y pasajeros de larga distancia, sin incluir los servicios proyectados. Lo pertinente aquí es la actualización del mapa (julio 2019) por lo que puede convertirse en una guía para la digitalización. También publica novedades acerca de los trazados: desde la suspensión de servicios en determinados días debido a problemas con la maquinaria o incidencias climáticas hasta las tarifas. Cuenta con una fanpage donde los aficionados comparten relatos de viajes que pueden ayudar a complementar la situación de algún ramal.

Como fuente no oficial, pero de suma importancia, sumamos a Ferromapas. Su objetivo es la construcción de un mapa ferroviario georeferenciado para Google Earth y así luego ser exportado a otras aplicaciones. El archivo $\mathrm{kmz}$ se divide en ramales y en los comentarios están sus autores. Todas las líneas cuentan con su respectivo nombre, al igual que las estaciones que forman parte de ellas junto al kilometraje que recorren las vías, siendo una fuente de gran valor para corroborar la información. La precisión es muy acertada a pesar de la multiplicidad de usuarios que han participado en su creación. Podemos pensar este trabajo como un mapa comunitario, por los distintos aportes que conforman el resultado final. Como dificultad, este archivo no especifica ningún tipo de variable en su tabla de atributos, únicamente muestra el recorrido de las líneas.

Otras bases de datos consultadas en Internet han sido las crónicas periodísticas y blogs, considerados fuentes secundarias, que se han vuelto pertinentes para el desarrollo de nuestra investigación y podrían serlo para otras. Con ellos hemos podido remitirnos a casos locales y obtener las voces de los miembros de las comunidades, pudiendo crear y dibujar las intenciones que la sociedad manifiesta frente algún hecho, en torno siempre a la problemática referida. Por esto, decidimos nombrarlos como otro recurso a tener en cuenta a la hora buscar fuentes para la elaboración de la base de datos.

Por último, entre las fuentes que se posicionan para el análisis a escala nacional podemos nombrar a la Enciclopedia de Ciencias y Tecnología en Argentina (ECyT-ar) de donde se pueden extraer datos como el origen de las líneas, inauguración, tipo de trochas, kilómetros recorridos, puntos conectados, entre otros. También publica los operadores de los ramales que funcionan actualmente. Cuenta con una cartografía creada por la Comisión Nacional de Regulación del Transporte donde se observa la totalidad de la red, distinguiendo los ferrocarriles y el estado operativo de cada uno, aunque su calidad de visualización no es óptima y su formato no admite modificaciones.

A nivel provincial, existe la Infraestructura de Datos Espaciales Santa Fe (IDESF). Es un geoportal donde se puede acceder a la visualización de gran variedad de elementos geoespaciales referidos a infraestructuras, datos socio-demográficos, ambientales, etc. Cumple la función de visor para el público en general, por lo que no es posible la descarga en ningún tipo de formato. Además, en lo concerniente a la estructura ferroviaria, sólo muestra recorridos sin aclarar su estado operativo o de infraestructura. Por su parte, el Instituto Provincial de Estadísticas y Censos (IPEC) complementa lo anterior con los shapefiles de los manzaneros o ejidos urbanos de las localidades de la 
jurisdicción provincial, datos necesarios para investigaciones localizadas. En el sitio del Gobierno de la Ciudad de Santa Fe se destaca la existencia de documentos, entre ellos el de las líneas de los trenes de carga que atraviesan la ciudad actualmente. En el mismo también se presentan proyectos que se han pensado para el municipio.

En suma, las fuentes consultadas reúnen una serie de potencialidades y limitaciones para el desarrollo de cartografía sobre el ferrocarril en la Argentina. Entre las primeras podemos destacar la exactitud de algunos trazados junto a la nomenclatura de cada ramal, lo que evita comenzar la elaboración desde cero. Además, al ser archivos.SHP permiten el acceso a través del software utilizado para desarrollar la investigación. Tener el respaldo de los organismos oficiales otorga mayor seguridad, pero -paradójicamenteencontramos aquí una de las mayores limitaciones. Gran parte de ellos no contaba con la precisión necesaria para avanzar, como tampoco una articulación entre ellos lo que genera grandes disidencias entre los datos que ofrecen. Por ello, no es recomendable fiarse de ellas, debiéndose proceder a métodos de triangulación de datos. Ante este panorama, en el cual la disparidad de la información conlleva a confusiones y errores en cuanto al estado de operatividad y al mantenimiento de la infraestructura ferroviaria, es necesario la implementación de un proceso de estandarización de la información.

\section{Propuesta metodológica}

Los trabajos antes mencionados han inspirado nuestra investigación, operando como antecedentes para su desarrollo, al tiempo que ratifican la relevancia de los SIG para estudiar y operar sobre las redes ferroviarias argentinas. Seguidamente, avanzaremos sobre nuestra matriz específica, la que hemos denominado Modelo de Acción para elaborar una Tabla de Atributos para la Construcción de una Cartografía Digital Ferroviaria Unificada. Optamos por el uso de un software libre como el QGIS (v 3.4), pensando en la facilidad de su manejo. Presenta características interesantes como la edición en PostGIS, conexión con GRASS, para tareas como edición de topología, y buen número de formatos soportados. Gilvert Margalef y Puig Polo (2008), Lejía Luna (2010), Campolesi y Paloma (2010) desarrollan las cualidades del programa comentando sus ventajas.

\section{Elaboración de la tabla/matriz de datos}

La planificación de la tabla de datos es esencial para la elaboración final de la cartografía como también el análisis de los elementos y sus variables. Así, "los datos son la materia prima necesaria para el trabajo en un SIG, y los que contienen la información geográfica vital para la propia existencia de los SIG” (Olaya, 2012:15). Teniendo esto en mente, presentamos una consideración general en el tratamiento de la información que aportan las fuentes: la tabla se origina, en primera instancia, con todos los datos hallados, sin importar las disparidades que hayan presentado. Es decir, importamos en ellas toda la información provista por las fuentes consultadas.

Seguidamente, se debe optar por un criterio para definir la nomenclatura, la codificación, la prioridad en la asignación de los mismos, etc. Este procedimiento se ha resuelto a partir de la aportación de Berry (1964), explicada por Gutiérrez Puebla y Gould (1994) para definir la matriz geográfica con el fin de relacionar las unidades espaciales o de análisis con los atributos temáticos de las variables. Es decir, éste es un lenguaje espacial propiamente dicho tal como expresa Harvey (1983), que a partir de los trabajos de los geógrafos denominados comúnmente "cuantitativos" se generaliza y adopta esa metodología de trabajo sobre los datos geográficos. Dichos datos organizados a través de esa metodología nos permiten recopilar y unificar la información 
ferroviaria recabada generando un inventario, ya sea de las fuentes o del trabajo de campo, estableciendo también una organización desde un punto de vista temático o de variables, como también la función principal que es la geolocalización.

Atendiendo al procedimiento sobre la búsqueda y, principalmente, la importación de datos que hemos mencionado, es que se ha optado por esta primera aproximación que ha definido Berry (1964) en la que no se tiene en consideración el componente temporal de los datos geográficos. Se alude a hechos y objetos del pasado como del presente, pero todos ellos han sido integrados en una misma tabla para la elaboración del modelo. En definitiva, las tablas elaboradas serán casos de "modelo relacional" que son aquellas en las que "las filas corresponden a los distintos objetos y las columnas a los atributos" pero que además cuenta con "una columna que recibe el nombre de clave primaria o identificador" para que ninguno de los elementos se repita y para poder enlazar tablas con sus atributos (Gutiérrez Puebla y Gould, 1994:117). En conclusión, en la elaboración de la tabla de atributos es importante recalcar la existencia de tres pilares: los elementos (desplegados en las filas), las variables (en las columnas) y, finalmente, la codificación de los elementos (la manera en que se nombran los datos). El tratamiento sobre cada uno de ellos dependerá de los objetivos, las escalas espaciales (y temporales), la manera en que se desee visualizar gráficamente en los SIG, etc. (Figura 1)

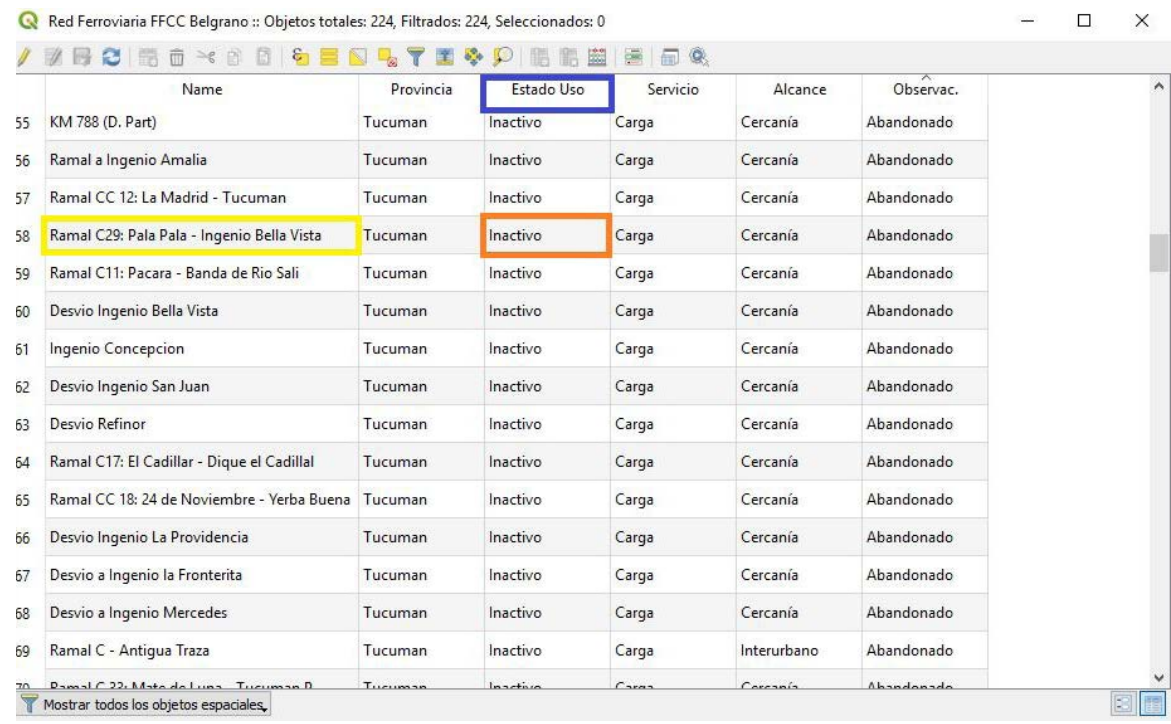

Figura 1. Matriz de datos donde se identifica con el recuadro azul a una variable; recuadro amarillo a un elemento; y recuadro naranja a la codificación de unos elementos según la variable seleccionada. Fuente: elaboración propia

\section{Sistematización de las fuentes de información}

Se advierte que las fuentes no siguen un mismo criterio al momento de definir el nombre de las variables que consideran y lo mismo ocurre con la codificación de los datos. Por ende, las nomenclaturas son distintas, cuestión que sucede tanto en fuentes primarias como en las secundarias. Casos concretos son el Ministerio de Obras Públicas y Viviendas (MIOPV), Trenes Argentinos Cargas y el Instituto Geográfico Nacional (IGN). El primero de ellos codifica la "operatividad" (es decir, el estado operativo o de funcionamiento de cada ramal) como "red sin operación o a demanda", "red primaria", "red secundaria", "no opera", mientras que el segundo simplemente como "en operación” y "sin circulación". Finalmente, el IGN presenta una sola categoría que es "activo". 
De esta manera es necesario que, al momento de realizar una investigación o plan de trabajo, exista un criterio claro y un marco común que unifique el procedimiento para gestionar, organizar, catalogar y adquirir la información de manera sistematizada. Así se evita que resulte disgregada o desarticulada, más allá de los objetivos específicos perseguidos. Caso contrario, se trabaja con fuentes que contienen objetos de diversa índole considerándolos como casos únicos en la terminología, cuestión que respondería a los propósitos particulares de cada trabajo.

La normalización permite que un proceso sea repetible y facilita su control. El problema se encuentra en qué relevar y cómo organizar los datos para lograr un uso adecuado de ellos y del conocimiento que se genere. Por ello, antes de comenzar cualquier proceso de captura de información se debería contar con un modelo de datos normalizado (Argerich, Montiveros, Mansilla, 2012). Es por ello que los organismos estatales dedicados a la conmutación de información espacial desarrollan lo que se denomina "Catálogo de Objetos Geográficos", para abstraer la realidad clasificada en datos cuyo nivel básico es el tipo de objeto. De esa manera se establecen bases para la interoperabilidad y el uso e intercambio de datos entre los diferentes usuarios, según IDERA (2019).

También cabe recalcar las acciones llevadas a cabo por la Infraestructura de Información Espacial en la comunidad europea con su directiva INSPIRE. Sucede que "la gran cantidad de redes de ferrocarriles europea necesitan de una sólida especificación geográfica que permita la interoperabilidad entre los diferentes Estados", y "hasta el momento, los Sistemas de Información Geográfica ferroviarios no han tenido en cuenta ningún patrón de normalización" (Gómez Castaño, 2012: 467). Dicha directiva prevé un nomenclador y otras directrices, como la construcción de una Infraestructura de Datos Espaciales (IDE) para el tratamiento de la información en softwares de uso libre de manera on-line, pensada como solución tecnológica adecuada para compartir y publicar todo tipo de información georreferenciada en una plataforma digital (Gómez Castaño, 2010).

En América Latina, se deben destacar los avances del Consejo Suramericano de Infraestructura y Planeamiento de UNASUR a través de su plan de Integración Ferroviaria de Suramérica en el cual se desarrolló un Sistema de Información Geográfico para dicho fin. Puede pensarse a futuro en la posible integración de las fuentes de datos procedentes de diferentes territorios para ser utilizados en la creación y explotación de cartografía ferroviaria por parte de las Empresas Ferroviarias y los Administradores de la Infraestructura de forma interoperable, incluyéndose los demás servicios de transporte.

A escala nacional, existen los nomencladores desarrollados por el Grupo de Expertos de las Naciones Unidas en Nombres Geográficos, garantizando la eficiencia en el uso de estos datos. En su portal, ofrece los nombres para cada uno de los ferrocarriles como también un visor para su localización. El IGN argumenta que se economiza tiempo y dinero al aumentar la eficiencia operacional, facilitando la construcción de cartografías. Este organismo entiende al nombre geográfico como "el nombre propio utilizado para designar un lugar, un accidente o una zona con una identidad reconocible sobre la superficie de la Tierra" (Instituto Geográfico Nacional, 2019). A partir de esto, han desarrollado el nomenclador geográfico según categorías, donde se encuentra la infraestructura de sistemas de transporte, englobando al ferrocarril.

De esta manera, se entiende que la prioridad por establecer criterios aplicables al proceso de normalización de vocabularios para ser capaces de eliminar barreras en los ámbitos del conocimiento, implica un correlato que contribuye a la difusión. Se deja en claro que los objetivos por los que abogamos son el de una metodología que intenta normalizar y sistematizar la información ferroviaria de la República Argentina con el fin de estandarizar la información y asegurar su compatibilización. 


\section{Criterios de definición de las unidades de análisis}

Hemos recalcado que este es uno de los tres pilares de la tabla de atributos siendo el primero a tener en cuenta, ya que es el estructurador de toda la información y el garante de cómo se observará la cartografía final. Sobre éste se aplican los otros pilares (variables y codificación) que, según cómo sean concebidos, será posible analizar y visualizar la información resultante. Basados en Borsotti (2009), la unidad de análisis será aquello sobre lo que se pretende producir conocimiento y, de esa entidad, surge la propiedad específica que interesa analizar. Para ejemplificar la idea, en nuestro objeto de estudio los ramales ferroviarios son la unidad de análisis, siendo definidos como los nombres de cada una de las líneas del tren. De allí se observa el estado de su infraestructura.

A decir de Gutiérrez Puebla y Gould (1994), "se puede afirmar que existen dos formas de individualización de las unidades espaciales, según se atienda a las 'propiedades' o a la 'localización' en el espacio" (Gutiérrez y Puebla, 1994:45). Pero ello debe ser ampliado con otros criterios que parten de los objetivos, las finalidades y la manera de recabar la información y los datos para definir la dimensión y delimitación de dichas unidades espaciales. Hemos optado por denominar a dicho procedimiento como una "delimitación subjetiva", esto implica que, partiendo de las propiedades, es decir de un atributo específico o la localización que sería simplemente una ubicación geográfica asignada al elemento, se establece un criterio propio según sea más conveniente, simplificando la manipulación de la información en la tabla. Se conjugan ambas maneras planteadas por estos autores, a los fines de delimitar las unidades espaciales acorde a las necesidades que posea la investigación que se realice.

Por otra parte, se puede optar por una delimitación objetiva, que implica en cambio mantener la segmentación original que otorgan las fuentes. En los trabajos en cuestión, se ha procedido a una mixtura de ambos procedimientos. Se ha partido de un criterio objetivo ya que se han tomado las geometrías de las unidades de análisis tal como fueron provistas por las fuentes, es decir a través de una individualización por propiedades (procedimiento habitual a la aproximación o modelo vectorial). Pero, a la vez, se ha optado por una lógica subjetiva en la que se delimitaron las mismas a criterio del investigador según dichas propiedades a fin de facilitar el trabajo.

Otra cuestión a atender es la escala espacial pues ella modificará las entidades geográficas. Por un lado, saber nombrar las unidades de análisis, y por otro la precisión del dato o atributo. Como se mencionó anteriormente, la labor con el SIG sobre los ferrocarriles se ha efectuado sobre dos escalas distintas: una nacional y la otra regional, en particular metropolitana (Gran Santa Fe), donde se han identificado distintas alternativas para poder definir las unidades de análisis y luego accionar sobre ellas. En esta instancia, el fin último es reflejar la realidad ferroviaria observada. Coincidiendo con el pensamiento de Hidalgo, Rosas y Strabucchi:

“(...) cartografiar las relaciones espaciales, procesos o estructuras de un determinado territorio -a partir de la información proveniente de distintas fuentes primarias, secundarias e incluso de descripciones de la ciudad registradas en diversos textos, documentos históricos y geográficos- y producir una visión de conjunto, es una forma de conocimiento." (2012: 63).

El abordaje de la totalidad de las redes es una posibilidad valiosa ya que permite la caracterización directa de las líneas sin la necesidad de añadir o sumar elementos a la tabla de atributos, por lo que la información resulta más reducida. De todas formas, debemos atender al contexto y comprender los distintos procesos que pudieron afectar la historia de las líneas, ofreciendo cualidades dispares en algún sector. Aquí yace una complicación que impediría el trabajo efectivo con el SIG. La otra alternativa es producir la cartografía a partir de la incorporación de ramales individualizados. El proceso se 
desarrolla añadiendo una capa shapefile perteneciente al Ramal CC (Retiro-Tucumán), por ejemplo, y se completa la información de ese elemento según las variables creadas. El paso siguiente, será el de volver a cargar un nuevo archivo SHP, perteneciente a otro ramal. Esta sucesión de etapas tendría como fin recomponer la totalidad de la red, pero se debería tener presente, nuevamente, la posibilidad de hallar zonas activas y otras inactivas en la misma traza. Ambos métodos comparten la misma problemática.

Como anticipamos, manipular la totalidad de un ramal resulta imposible si lo aplicamos a las complejidades de la trama férrea argentina. Al clasificar la red según su estado operativo (Figura 2) ésta refleja múltiples fragmentaciones, por lo que es una dificultad si se quisiera trabajar con esos objetivos a escala nacional.

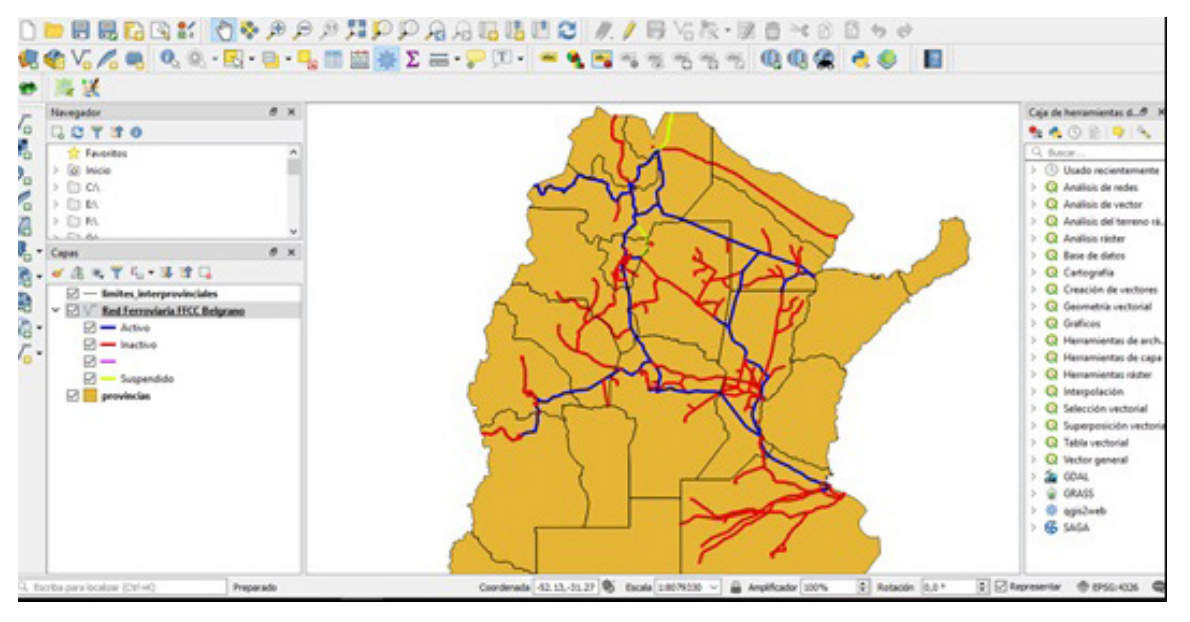

Figura 2. Red del Ferrocarril Belgrano según su estado operativo. Fuente: elaboración propia

Gran parte de las líneas activas no operan en todo su trazado, por lo que se subdividen continuamente. Si observamos el comportamiento del Ramal F del Ferrocarril Belgrano, con origen en Santa Fe y destino final en Barranqueras (Chaco), se diferencia en tres sectores según su estado de operatividad (Figura 3).

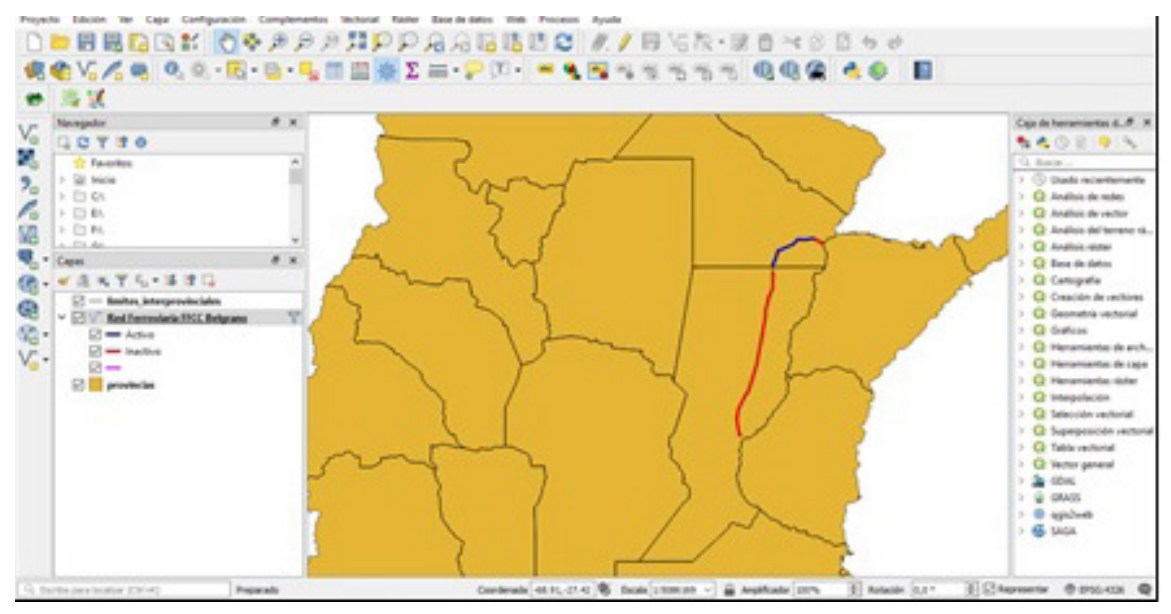

Figura 3. Ramal F Santa Fe-Barranqueras del Ferrocarril Belgrano según su estado operativo. Fuente: elaboración propia 
Es por ello que, si en la cartografía a producir se pretendiera diferenciar operativoinactivo, una metodología válida sería seccionar los ramales utilizando algún tipo de división político-administrativa. Por ejemplo, realizar un recorte a partir de los límites de la provincia de Santa Fe u otras (Figura 4). Esta técnica facilita y simplifica la diversidad de características que pudieran aplicarse a una línea, principalmente en aquellas que atraviesan varias provincias. Como debilidad del procedimiento, la tabla de atributos sería más extensa que en el resto de las alternativas, debido al agregado de elementos.

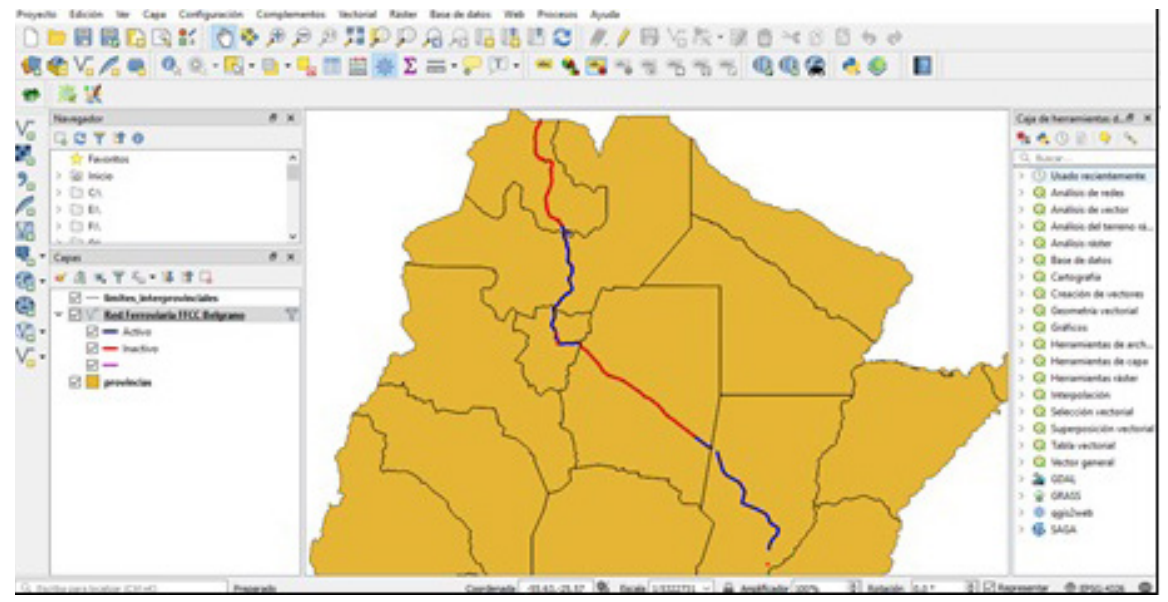

Figura 4. Recorrido de la Línea $C$ del Ferrocarril Belgrano en distintas jurisdicciones provinciales según su estado operativo. Fuente: elaboración propia

En las Figuras 3 y 4 se aprecian recorridos del Ferrocarril Belgrano confeccionados utilizando los límites provinciales para poder determinar las cualidades que presenta su trazado en una escala reducida, pudiendo así precisar y facilitar el proceso. Además, este procedimiento permite realizar cartografías provinciales, clasificando los ramales a partir de alguna otra variable. A partir de este accionar es clara la expresión de que cada mapa habla la lengua de sus autores, y con este modelo queremos compartir otra manera de avanzar en trabajos con SIG sobre cuestiones ferroviarias. De forma complementaria al uso del software, en ambos mapas se observa la particularidad de que, en cada jurisdicción provincial, el estado operativo de la línea es diferente. Esto sugiere una interpretación política que nos remonta al momento de las privatizaciones cuando algunos ramales de pasajeros interurbanos fueron cedidos a las provincias.

Por su parte, la manipulación a escala regional permite analizar y problematizar el trazado del ferrocarril desde otra mirada espacial. El caso del Área Metropolitana de Santa Fe se halla atravesado por la existencia de ramales ferroviarios tanto activos como desafectados que cruzan las localidades del aglomerado. Pero, a la vez, se vuelve un caso particular de atención a causa del proyecto del Ministerio de Transporte de la Nación denominado Plan Circunvalar Ferroviario, el que afecta dicha área y dejará desafectados los ramales hoy activos del Ferrocarril Belgrano.

Al poner la mirada sobre localidades, la vectorización de los recorridos adquiere mayor precisión. De esta forma se visualizan las áreas político-administrativas propias de cada localidad, como también el parcelario y manzanero urbano-rural actualizados afectados al llevar a cabo el proceso de superposición de capas en el entorno SIG. La cartografía del municipio ha sido superpuesta al trazado ferroviario para corroborar una serie de cuestiones: primero ver si las trazas férreas atraviesan las parcelas tanto rurales como urbanas. Por otro lado, cuando no se respeta el trazado intersticial entre parcelas, por 
el cual debería desplegarse dicho trazado férreo, se verifica que puedan ser extensiones sin circulación o que no existan, situación que amerita proceder al trabajo de campo. Asimismo, éste permite corregir problemas de topología, acciones que se han llevado a cabo usando las herramientas propias de corrección topológica del software QGIS.

Atendiendo a las directrices presentadas en el caso de estudio anterior, la metodología para delimitar y definir las unidades de análisis para la escala metropolitana es la misma en cuanto a las opciones a aplicar. Pero las implicancias específicas que atañen a esta escala precisan de mayor detalle en la asignación de datos para cada uno de los elementos a considerar. De esta forma, se ha procedido a la siguiente solución: debido a que cada variable considerada aporta distintos atributos a lo largo del recorrido, según cada una de las unidades de análisis, las mismas se duplican por la cantidad de veces que dicho atributo así lo precise. Por ello, se repite el nombre del elemento o unidad de análisis agregando una letra que lo diferencie del anterior o del siguiente en la columna NOMBRE, evitando así una superposición de las geometrías (Figura 5).

\begin{tabular}{|c|c|c|c|c|c|c|}
\hline ID & NOMBRE & OPERATIVIDAD & ESTADO INFRAESTRUCTURA & TROCHA & SERVICIO & OBSERVACIONES \\
\hline 1 & 9 Santo Tome - Santa Fe & Sin circulacion & Inexistente & Mixta & Carga & Ramal antiguo ... \\
\hline 0 & 10 Santo Tome - Santa Fe A & Sin circulacion & Existente & Ancha & Carga & Sin relevar \\
\hline 1 & 11 Linea F: Santa Fe - Vera (Tren Urbano) & En operacion & Existente & Angosta & Pasajeros & \\
\hline 2 & 12 Linea F: Santa Fe - Vera A & Sin circulacion & Inexistente & Angosta & Carga & \\
\hline 3 & 13 Linea F: Santa Fe - Vera B & Sin circulacion & Existente & Angosta & Carga & \\
\hline 4 & 14 Linea F2: Santa Fe - Rafaela & Sin circulacion & Existente & Angosta & Carga & \\
\hline 5 & 15 Linea F2: Santa Fe - Rafaela A & Sin circulacion & Inexistente & Angosta & Carga & \\
\hline 6 & 16 Linea F2: Santa Fe - Rafaela B & Sin circulacion & Inexistente & Angosta & Carga & Sin relevar \\
\hline 7 & 17 Ramal F1: Santa Fe (FCSF) - Rosario (FCSF) & En operacion & Existente & Angosta & Carga & \\
\hline 8 & 18 Ramal F1: Santa Fe (FCSF) - Rosario (FCSF) A & En operacion & Existente & Angosta & Carga & Disidencia de d... \\
\hline 9 & 19 Ramal F1: Santa Fe (FCSF) - Rosario (FCSF) B & Sin circulacion & Existente & Mixta & Carga & \\
\hline 0 & 20 Ramal F1: Santa Fe (FCSF) - Rosario (FCSF) C & Sin circulacion & Inexistente & Angosta & Carga & \\
\hline 1 & 21 Ramal F1 Empalme Santa Fe (FCSF) y FCGBM & En operacion & Existente & Angosta & Carga & Sin relevar \\
\hline 2 & 22 Ramal F1 Empalme Santa Fe (FCSF) y FCGBMA A & En operacion & Existente & Mixta & Carga & Sin relevar \\
\hline 3 & 23 Ramal F1 Empalme Santa Fe (FCSF) y FCGBM B & Sin circulacion & Existente & Ancha & Carga & Sin relevar \\
\hline 4 & 24 Ramal F1 (Antigua Traza Santa Fe) & Sin circulacion & Inexistente & Angosta & Carga & \\
\hline
\end{tabular}

Figura 5. Subdivisión de elementos. Fuente: elaboración propia.

Obsérvese que en los casos seleccionados, en color amarillo y verde, existen mínimas diferencias a lo largo del trayecto de una misma unidad de análisis. Repetirlo y diferenciarlo con una letra permite especificar precisamente las diferencias de los atributos con respecto a las variables. Es así que algunas ventajas de este procedimiento son las de lograr una visualización y a la vez una consulta rápida a la hora de la observación de los elementos bajo análisis. Esto es porque al poseer una tabla de atributos ordenada, se puede determinar en qué sector específico del elemento que se analiza se encuentra dicha diferencia.

No obstante, se debe evitar la multiplicidad de unidades de análisis, por así decirlo de manera infinita, particularmente cuando se analiza la variable infraestructura, la cual presenta dicha particularidad en relación a los atributos que van cambiando por sectores. Es así que también está la posibilidad de aplicar un valor general a la unidad para evitar dicho inconveniente. Esta sería una posibilidad, pero también se desataca la opción de generar un shape por cada variable para poder enfatizarlas. Pero además esta última opción es la que favorecerá la aplicación de distintos procesos de análisis espacial, como también geoprocesos. 


\section{Variables y codificación de los datos: definición de nombres y propiedades}

La definición de la nomenclatura es un paso previo importante, de forma que podamos tener en claro los nombres de cada unidad o elemento. Para nombrar cada ramal es necesario partir de una fuente de referencia que otorgue el dato, para luego comparar con otras fuentes en cuanto a la nomenclatura. Se recomienda realizar una observación y análisis de éstas para verificar el nivel de rigurosidad. Los organismos oficiales son una herramienta pertinente, aunque existen otros medios que brindan más exactitud. Esto ocurre con Ferromapas que, incluso, es citada por ADIF licitaciones.

Recalcamos nuevamente la existencia del nomenclador del IGN como fuente primaria para poder nombrar a los objetos espaciales, pero atendiendo también al detalle con el cual trabaja Ferromapas. Finalmente, debe hacerse uso de un punto de vista propio para simplificar y clarificar los nombres en el caso de advertir ambigüedades y/o confusiones. Retomando las consideraciones sobre los criterios objetivos y subjetivos que han sido mencionados, si se observan las figuras 6 y 7 podrán apreciarse ambos criterios. La primera muestra el caso objetivo, que es aquel en el cual se toman los datos que aportan las fuentes tal como han sido provistos por éstas. Mientras que la segunda muestra el caso de la combinación de datos de las fuentes con sus respectivos límites, pero según el criterio de delimitación que adopte el investigador.

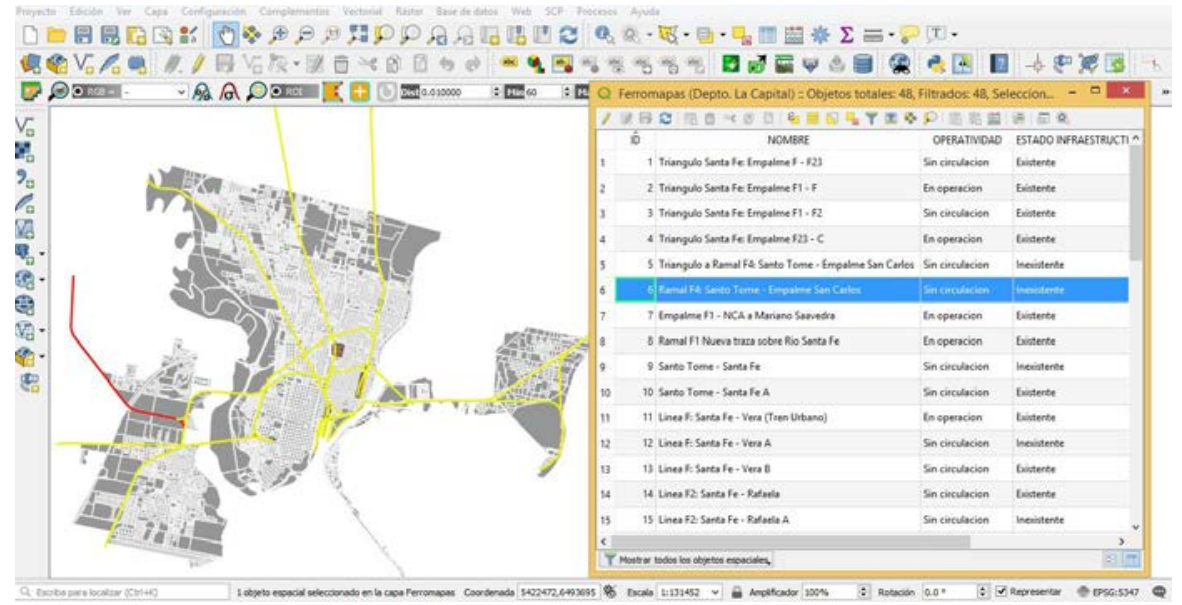

Figura 6. Criterio objetivo aplicado sobre Ramal F4: Santo Tomé - Empalme San Carlos. Fuente: elaboración propia

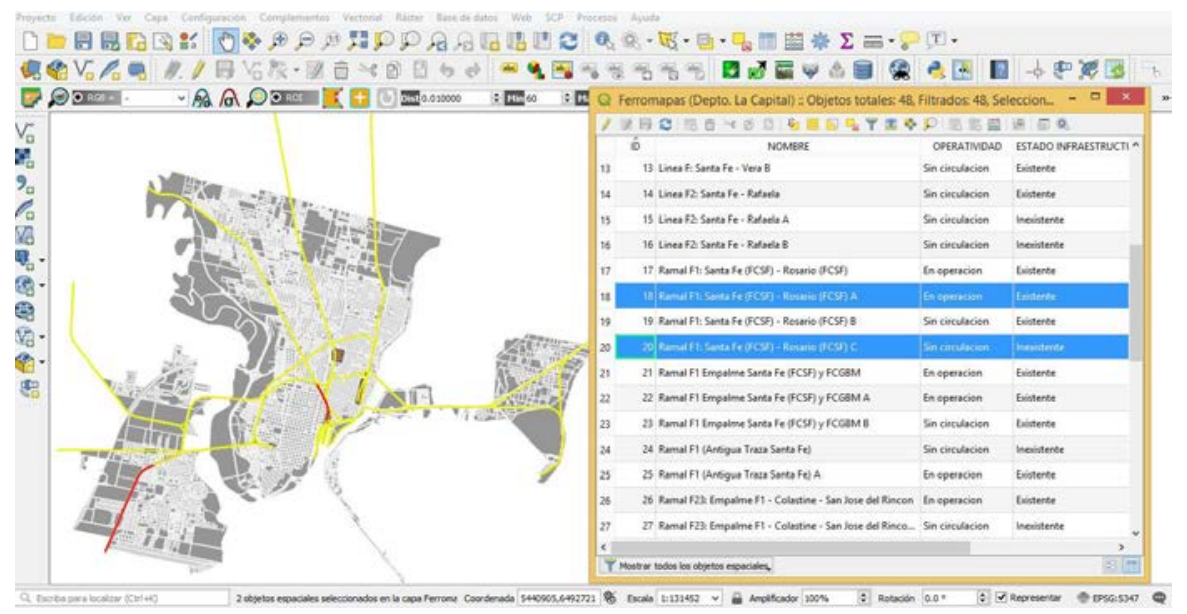

Figura 7. Criterio subjetivo aplicado sobre Ramal F1: Santa Fe (FCSF) - Rosario (FCSF). Fuente: elaboración propia 
Por otra parte, como venimos mencionando a lo largo del artículo, el manejo del software varía según los objetivos planteados por el investigador, por lo que se hace pertinente recordar que las sugerencias propuestas refieren a la elaboración y análisis de cartografía digital sobre redes ferroviarias, en base a nuestra labor sobre el caso argentino. Es por ello que a partir de este punto avanzamos sobre las variables a utilizar. Los caminos considerados para definir las propiedades podrían ser dos. Podríamos optar por categorías creadas por otros autores que acompañan a los archivos SHP descargados desde la fuente. Esto puede llevar a cierta rigidez ya que deberíamos adaptarnos a la información ya procesada. Por otra parte, sería posible crear variables propias atendiendo a nuestras necesidades investigativas. Creemos que ésta es la forma más viable para evitar caer en equivocaciones futuras en el manejo del SIG.

Si tomamos como ejemplo uno de los casos, seleccionamos un elemento (ramal) y allí incorporamos información a cada variable diseñada por los investigadores: la operatividad del ramal (en operación o sin circulación), estado de la infraestructura (existente o inexistente), tipo de trocha (angosta, media, ancha o mixta), el servicio que brinda (carga, pasajeros, pasajeros de larga distancia, mixto, de cercanías, urbano, turístico), y la gestión (pública o privada), cada una debe definirse con antelación para establecer un parámetro de la información que se sumará a cada elemento, es decir, prever las ambigüedades en la tabla de atributos.

De esta manera, dimos cuenta del valor de este conjunto de variables creadas para luego poder confeccionar cartografías sobre la infraestructura del ferrocarril, conjuntamente de los posteriores análisis. Si bien esto se torna una labor exhaustiva, principalmente al intentar identificar las características de ramales desafectados recientemente o en un estado inactivo, seleccionando metodologías o recursos diferentes para averiguar la situación de cada caso, dimos cuenta que son datos fundamentales para entender ciertas dinámicas que hacen al tren, y las intenciones y énfasis puestos en la compleja red. Incluso permite interpretar de forma básica las lógicas territoriales de tiempos anteriores, plasmados en las líneas del Belgrano, particularmente.

Para retomar la cuestión sobre la definición de variables, a continuación se presentan algunas consideraciones, con una aproximación a sus definiciones, ya que la codificación consiste en reunir o agrupar información o circunstancias similares que hayan sido inventariadas.

Con respecto a la operatividad el código sin circulación refiere al no funcionamiento del ramal, sin indicar la existencia o no de la infraestructura. Las posteriores variables servirán de complemento a esta información. La infraestructura, en cambio, muestra la presencia o inexistencia de infraestructura alguna referida al ramal bajo análisis. Sucede que se presentan casos donde los rieles existen, pero las condiciones en las que se encuentran no permiten la transitabilidad. Por ejemplo, sectores donde la vía está sellada por asfalto. Para sumar esta información, se debe crear una nueva variable denominada observación, lo que permite identificar estas particularidades que son importantes para comprender la situación del ramal. Por último, es preciso considerar la trocha, cuya relevancia reside en la influencia que ejerce en cuestiones de integración territorial. Esto también remite a la idea de que cada empresa ha impreso en el territorio un tipo de trocha distinta. En consonancia a esta cuestión de nombres, es importante tener en cuenta que en algunas fuentes varían dichas denominaciones.

Por otro lado, la codificación -definida por el IGN e IDERA como las características que describen e informan sobre los objetos geográficos- puede presentar distintas cualidades. En nuestra investigación han sido datos no espaciales que describen las características de las capas gráficas y los fenómenos que ocurren en localizaciones geográficas específicas. Lejía Luna (2010) clasifica a estos atributos de tres maneras: atributos nominales, para referirse a las entidades geográficas con información descriptiva 
(cualitativa o cuantitativa) acerca de las características que asume la fisonomía del mapa. Por otra parte, añade los índices geográficos, para señalar los incidentes o fenómenos que ocurren en una localización específica, sin describir rasgos del mapa en sí mismo, y los vínculos espaciales que son descripciones conceptuales entre los objetos espaciales. Las asociaciones espaciales son definidas principalmente como descripciones de proximidad, adyacencia y conectividad de los rasgos del mapa.

$\mathrm{Al}$ tener diseñada la tabla, junto con sus respectivas variables y, en cada una de ellas, el atributo correspondiente, ese esqueleto vertebrador está listo para elaborar una cartografía sobre la temática, sumado a los múltiples análisis y consultas espaciales que pueden elaborarse con el SIG para producir conocimiento novedoso. A fin de obtener ese producto, es necesario que la tabla sea cargada de información de manera correcta. En caso contrario, el error alteraría todos los resultados posteriores.

\section{Procedimiento para completar las variables}

Los siguientes pasos están pensados para no caer en imprecisiones a la hora de interactuar y completar la tabla de atributos con la información correspondiente. El objetivo aquí es el de añadir los datos de manera exacta y agilizar el trabajo como también una propuesta de normalización en el proceso de la carga de los atributos temáticos. El primer paso está basado en la selección de una fuente base para definir nombres de elementos de las unidades de análisis. Luego, se deberá trabajar de forma individualizada cada uno de los elementos, contrastando con otras fuentes, por ejemplo, puede sumarse una cartografía analógica o en papel para ir verificando el contenido.

El proceso para completar las variables puede efectuarse de dos maneras: seleccionar una variable (columna) y agotar todos los campos o identificar un elemento y completar toda la información según las variables creadas. Recomendamos trabajar sobre una misma variable en cada uno de los elementos. Esto admite mayor velocidad como también precisión ya que se conoce previamente cuáles serán las fuentes o shapes que poseen dicha variable, agilizando entonces el procedimiento para importar datos (Figura 8). Caso contrario, pueden producirse confusiones en los datos, lentitud en la búsqueda de las fuentes, etc., debido a que en cada elemento se tendría que completar todas las variables al trabajar la totalidad de las fuentes y shapes al mismo tiempo.

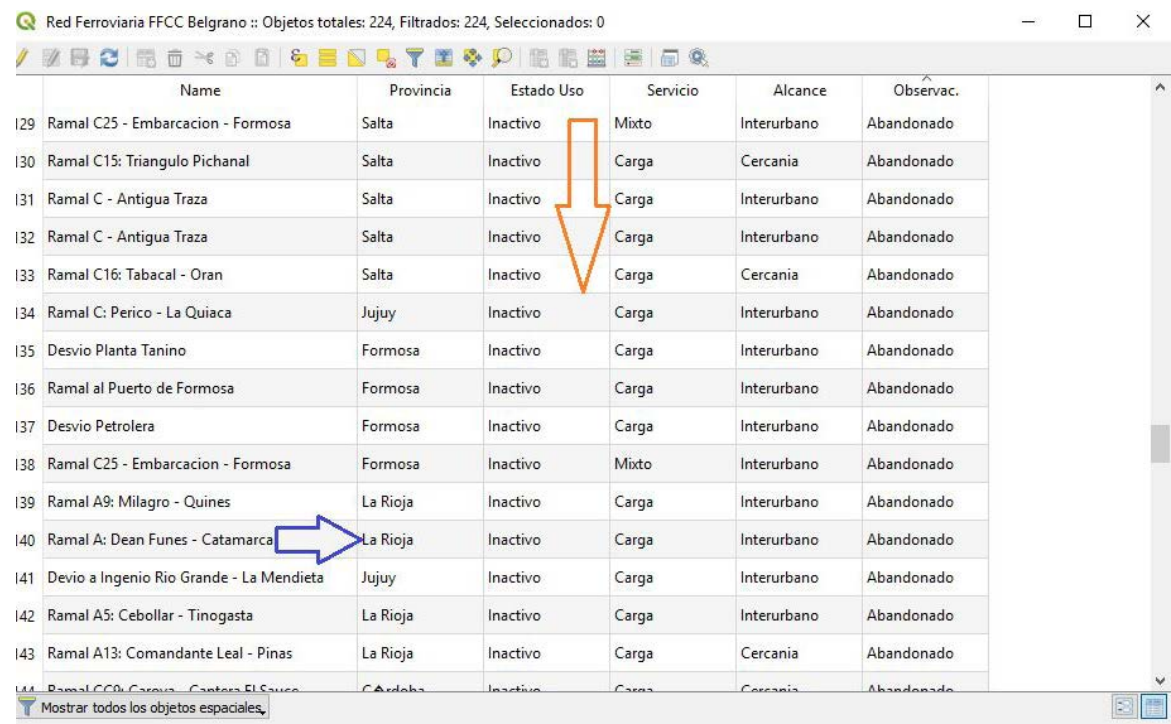

Figura 8. Tabla de atributos con las dos alternativas para completar la tabla de atributos. La flecha naranja indica la primera forma explicada: completar el estado operativo de todos los ramales; según la línea azul, la tabla debería elaborarse introduciendo todos los datos del Ramal A: Dean Funes Catamarca, para luego realizar el mismo procedimiento con los siguientes. Fuente: elaboración propia 
Siguiendo esta lógica, es importante hacer hincapié en el diseño de las tablas, ya que es lo que permite mostrar la información relevante y de forma correcta. Un mal diseño alteraría la interpretación del proyecto y causaría cambios en la cartografía. Pero, por otra parte, es fundamental establecer un orden de importancia en la consulta de las fuentes según sus variables al momento de contrastarlas entre sí (Cuadro 1).

Cuadro 1. Fuentes a utilizar, según su rigurosidad de tratamiento, para el trabajo de cada variable. Fuente: elaboración propia.

\begin{tabular}{|l|c|c|c|c|c|}
\hline Nombre & Operatividad & Infraestructura & Trocha & Servicio & Concesión \\
\hline Ferromapas & TAC & Candioti y otros & TAC & ADIF & TAC \\
\hline TAC & ADIF & Seval y otros & ADIF & $\begin{array}{c}\text { Municipalidad } \\
\text { de Santa Fe }\end{array}$ & ADIF \\
\hline ADIF & $\begin{array}{c}\text { Candioti y } \\
\text { otros }\end{array}$ & & MIOPV & $\begin{array}{c}\text { Satélite } \\
\text { Ferroviario }\end{array}$ & MIOPV \\
\hline & Seval y otros & & IRSA & MIOPV & IRSA \\
\hline & MIOPV & & IGN & IRSA & \\
\hline & IRSA & & & & \\
\hline & $\begin{array}{c}\text { Satélite } \\
\text { Ferroviario }\end{array}$ & & & & \\
\hline & Map Cruzin & & & & \\
\hline
\end{tabular}

Otra dificultad que podría presentarse es la disidencia entre los datos hallados, por ejemplo, el estado operativo de un ramal se define como activo en un sitio, inactivo en otro, y suspendido en un tercero. Ante esta situación, se procura una posible solución. En primera instancia, para confrontar los datos de las distintas fuentes, debe otorgarse relevancia a la fuente de confianza y posteriormente a la fecha de elaboración de las fuentes, depositando mayor confianza en la más reciente. Otro factor preponderante es la escala ya que ello determinará el grado de exactitud y detalle de los recorridos ferroviarios. Estas directrices se piensan principalmente para casos de estudio de escala local, ya que la lógica para decidir la relevancia de las fuentes cambiará con la escala asignada y trabajada.

En segundo lugar, si se advirtieran disparidades groseras, esta metodología sugiere emplear la herramienta Street View de Google Maps, que permite observar el territorio como si nos encontráramos en él, ahorrándonos las tareas del trabajo in situ. A partir de dicha herramienta se recomienda la creación de un catálogo de capturas de imágenes ya que permitirá su consulta de manera veloz si fuera preciso volver al elemento, sin necesidad de ingresar a la aplicación. Además, realizar un catálogo permite preservar una serie de fotos sistematizada y ordenada para dictaminar cómo se denomina el elemento o el año de la imagen, cuestiones que ante una nueva búsqueda en la aplicación podrían verse sujetas a modificaciones.

Podría ocurrir que el elemento (ramal/vía férrea) sea muy extenso para ser verificado con la captura de imágenes, como también que los datos a relevar para una variable específica sean infinitos o de una gran variabilidad espacial que dificulte el estudio de toda la realidad. Se sugiere entonces la realización de un muestreo. En términos de Gutiérrez Puebla y Gould (1994:63), la muestra "es seleccionada con el objetivo de captar la variación espacial de un universo mucho mayor. Para asegurar que la muestra es representativa de ese universo, es necesario recurrir a las técnicas de muestreo espacial". Harvey (1983), también explica que el fin práctico del muestreo es reducir a una matriz de datos pequeña una enorme cantidad de información. 
De esta forma, podemos optar por un muestreo de tipo sistemático con el cual tomar un mínimo de capturas de imágenes de manera equitativa sobre el espacio en el cual se despliega el elemento. Por ejemplo, una (1) al comienzo del mismo, dos (2) en su tramo medio y nuevamente una en su finalización. De esta manera se logra dar cuenta de la variedad de situaciones que suceden sobre el mismo, subdividiendo el elemento según la cantidad de veces en que el atributo se modifique. En cambio, frente a esa diversidad de casos específicos, el investigador también tiene la opción de seleccionar de manera general un atributo para asignar al elemento en su totalidad. Así puede evitarse el trabajo de subdividir en varios elementos un mismo ramal o vía.

Este método específico muestral se enmarca en los denominados intencionales o intuitivos. "En las primeras etapas de una investigación, tiene un papel importante. Pero no hay forma alguna de saber cómo y en qué aspectos está sesgada la muestra elegida" (Harvey, 1983: 362). Esta alternativa es considerable a fines de publicaciones o visualizaciones que se piensen al público en general con objetivos de comunicación. Finalmente, si la aplicación no posee imágenes del sector en cuestión o las imágenes que brinda son anteriores a las propias de las fuentes, se procederá al relevamiento in situ, si las condiciones así lo permiten.

\section{Oportunidades de un SIG: cartografiado y análisis espacial}

La meta del SIG es crear, compartir y aplicar útiles productos de información, salidas gráficas, es decir, mapas, como uno de los resultados más sobresalientes de estos softwares. Es decir, no se trata sólo de almacenar información, sino que también tienen una salida cartográfica, mapas a diversas escalas con distintas proyecciones y distintas representaciones temáticas. Por eso, adherimos a las afirmaciones de Sánchez Ayala (2012), al plantear que la capacidad de almacenamiento y procesado posibilita la observación de grandes cantidades y complejos datos espaciales por medio de mapas, gráficos, histogramas, animaciones y visualizaciones tridimensionales. "Los datos espaciales y sus relaciones son inherentemente difíciles de describir en texto, por lo que se requiere un método de comunicación con "información densa". En ese sentido, la forma más común de visualización de los SIG es el mapa” (Gutiérrez Puebla, 1994:21).

Como es sabido los distintos programas de SIG cuentan con la oportunidad de crear los vectores que serán representaciones espaciales de la realidad. Las geometrías o entidades espaciales que permite manipular son líneas, puntos o polígonos, optando por algunos de ellos dependiendo de las figuras que se quieran digitalizar. Las líneas como entidad geométrica espacial son "de una dimensión, ya que tienen longitud, pero no anchura (...) estando definidas mediante una sucesión de puntos" (Gutiérrez Puebla y Gould, 1994: 99). Claramente es la entidad cuya expresión espacial es la que mejor se ajusta a la representación de vías férreas. Se puede hacer uso de digitalizaciones ya elaboradas o comenzar nuevas. Los impedimentos que puede ocasionar la primera opción son los límites impuestos por el objetivo mismo del trabajo. Es decir, el mapa creado hace hincapié en cuestiones que exceden o son irrelevantes para nuestro trabajo particular. Allí radica la ventaja de la segunda variante en la que podemos modelar los vectores según nuestros intereses.

Igualmente, podemos manipular un shapefile modificando o construyendo segmentos de importancia para el propio trabajo. A continuación, se mostrará mediante imágenes cómo ha sido el proceso de trabajo dentro del entorno QGIS (Figuras 9 y 10) en sus versiones 2.18 y 3.4 . 
Proyecto Edición Ver Capa Configuración Complementos Vectorial Ráster Base de datos Web SCP Proce

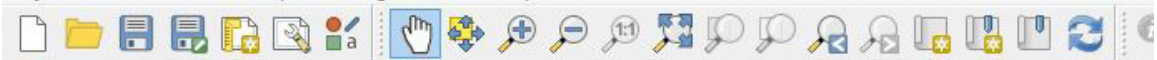

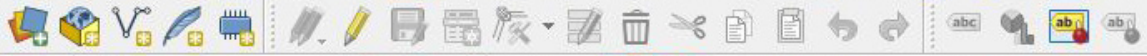

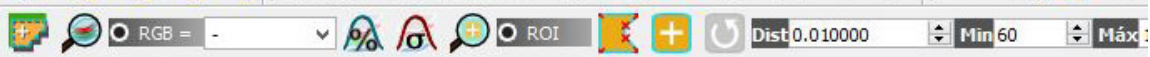

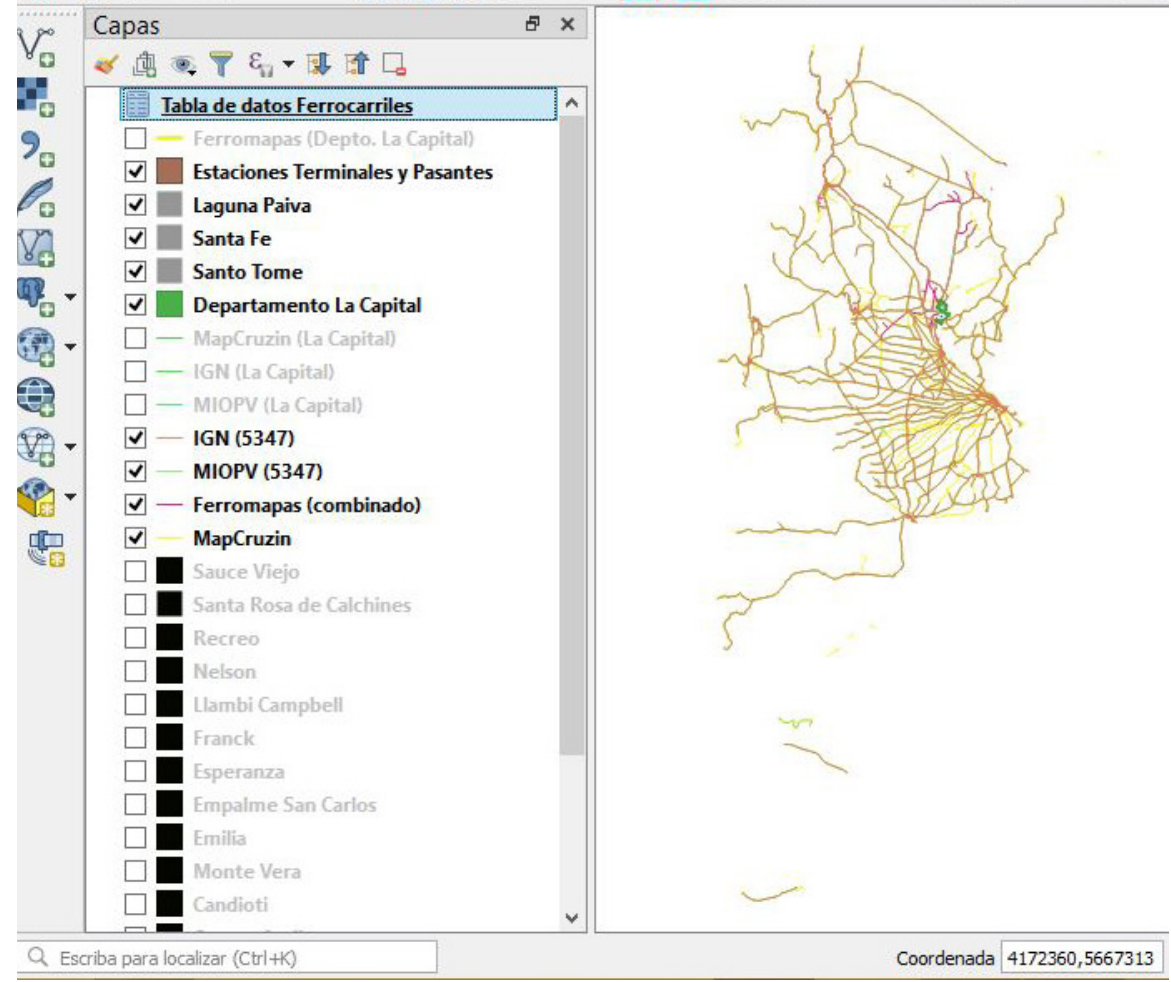

Figura 9. Superposición de los shapes empleados. Fuente: elaboración propia 


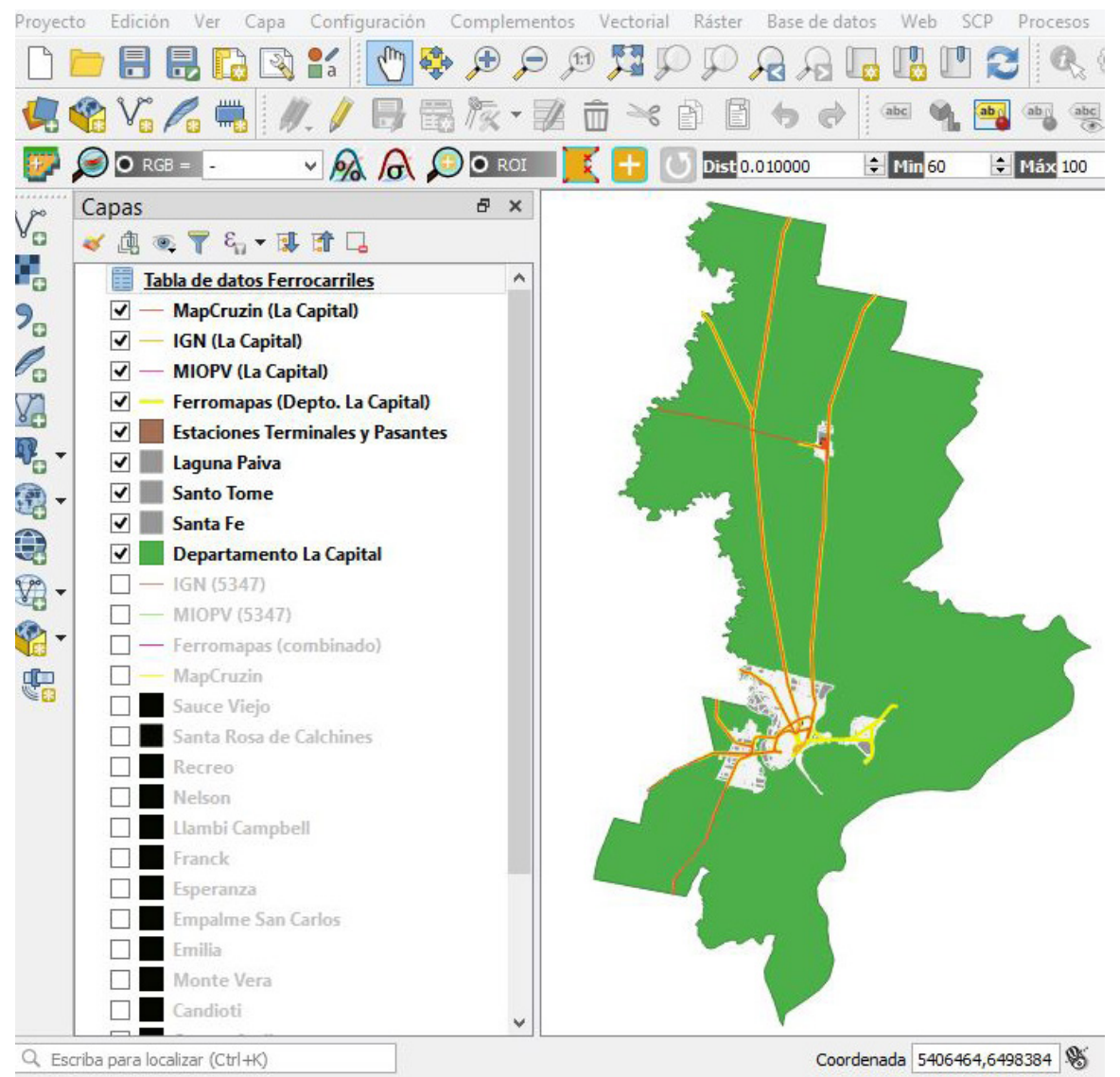

Figura 10. Delimitación de shapes empleados. Fuente: elaboración propia

La serie de imágenes revela el procedimiento efectuado para obtener la delimitación sobre las vías férreas a partir del área de estudio definida. En este caso nos referimos al departamento La Capital (Provincia de Santa Fe) otorgando interés a tres municipios. Por ello, se activan los shapes de los distritos, se recorta el caso de estudio y, finalmente, teniendo el mismo como área se continúa con el recorte de las líneas férreas. Si existieran vías pertenecientes a distintas empresas procedemos a unificarlas en un shape a fin de facilitar posteriores análisis con las herramientas del software.

En el siguiente caso (Figura 11), se observa la parte que corresponde al tendido férreo del Ferrocarril Belgrano, discriminando las líneas a partir de su operatividad. La captura pertenece al norte del país, donde los rieles en actividad llegan hasta los límites nacionales en dos casos. De todas formas, gran parte se halla en estado inoperable, sin vistas a la modernización y vuelta al servicio (la elaboración de la cartografía corresponde a mayo de 2019, por lo que podría ocurrir que el ministerio haya avanzado en algunas obras que aquí no figuren). 


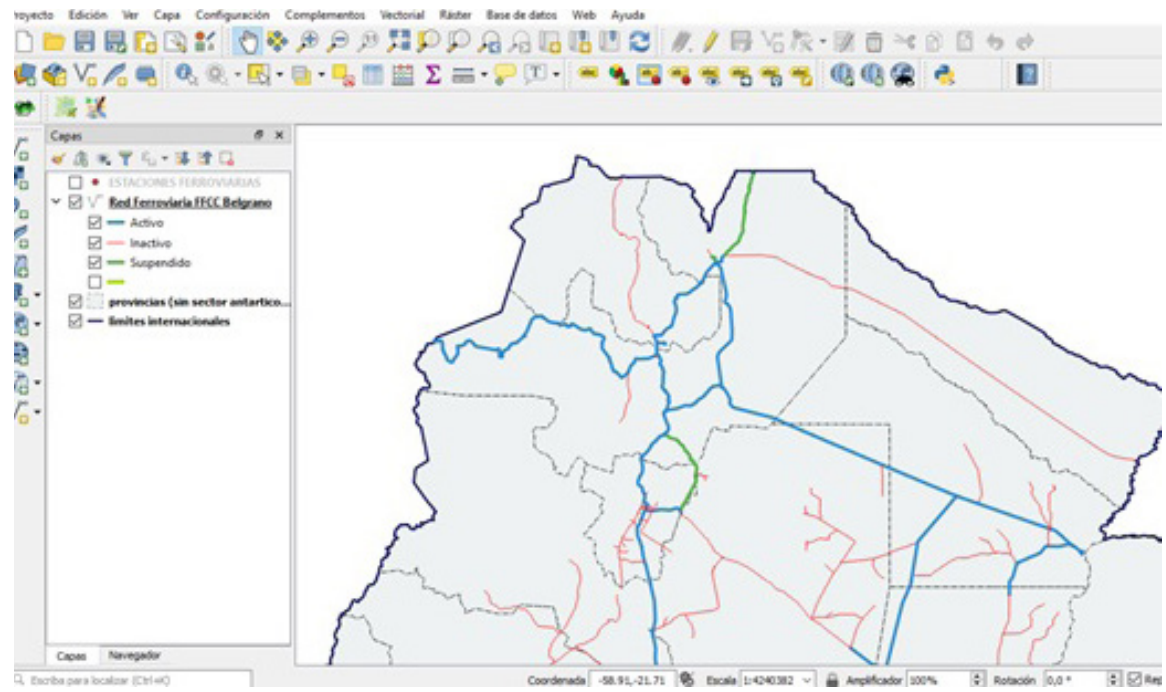

Figura 11. Líneas férreas del Belgrano en el NOA. Fuente: elaboración propia

Una vez elaborada la cartografía se pueden desarrollar distintas funciones con el SIG, con el fin de realizar un análisis de la situación espacial que, a simple vista, es difícil determinar. Nos referimos a las consultas espaciales, representando una ayuda en la toma de decisiones en función a alguna inquietud. Campolesi y Paloma (2010) afirman que las consultas abarcan desde operaciones simples, como visualizar algún elemento en particular, hasta situaciones complejas, como ser la aplicación de geoprocesos u operaciones lógicas. Yace aquí una de las principales especificidades de estos softwares que, además, se encuentra en una posición más avanzada con respecto a los programas de diseño $\mathrm{CAD}$, ya que permiten almacenar, manejar, procesar y analizar información. Así, procesos tediosos que debían desarrollarse manualmente, mediante la sistematización de los datos en los softwares especializados ahora pueden desarrollarse en tiempos considerablemente menores y con mayores niveles de eficacia.

\section{Reflexiones finales}

Si bien el SIG es una herramienta en gran medida cuantitativa para analizar datos y representarlos cartográficamente, puede valorarse su importancia para las ciencias sociales entendiéndolas como cuerpo científico donde predomina la información cualitativa. Los SIG han resuelto problemáticas en distintas áreas, más allá de su aporte netamente geográfico-espacial. En lo que refiere a esta disciplina, se ajusta al análisis de los ferrocarriles argentinos y, puntualmente, al estudio de la modernización del Ferrocarril Belgrano en las últimas décadas. La correcta utilización del software, manteniendo criterios y objetivos claros, recae sobre la elaboración cartográfica y permite reflexiones sobre la ordenación del territorio donde yacen disputas y acuerdos entre la multiplicidad de agentes espaciales. Igualmente, debe advertirse que su utilización aún está sesgada y podría limitarse a una reducida serie de movimientos mecánicos, restando elementos críticos sobre el espacio y sus componentes. Por ello, es necesario tener una mirada inquisidora sobre el proceso de carga de datos evitando su naturalización y neutralidad.

Consideramos que la cartografía proporciona una valoración rápida e intuitiva sobre determinadas variables e información geolocalizada en el espacio, apuntando a posibles y necesarias intervenciones futuras, atendiendo al contexto de renovación ferroviaria 
impulsado desde el Estado nacional. Bajo esta perspectiva de gestión de inventarios integrada a un SIG, definimos esta propuesta metodológica como una contribución para la detección visual de información relevante. Asimismo, el modelo admite generar consultas rápidas espacialmente diferenciadas gracias a la modalidad de integración que posibilitan dichos sistemas. Este trabajo ha permitido unificar, sistematizar y procesar información sumamente dispersa sobre la actual situación del Ferrocarril Belgrano en la Argentina, en un esfuerzo de investigación de interés académico, comunicativo y como posible aporte para la elaboración de políticas públicas.

De esta forma, la cartografía se vuelve una herramienta de reflexión comprometida del geógrafo para tomar decisiones sobre problemas territoriales, pero exige superar las meras abstracciones y análisis de formas y entidades geométricas espaciales vacías, manteniendo también un orden y lógica de la información producida. Por ello, el próximo paso de nuestra investigación será analizar las implicancias socio-económicas de las representaciones obtenidas como base de datos para futuras indagaciones.

Por ejemplo, fuera de la practicidad del programa, el ferrocarril ha generado distintas miradas a lo largo de la historia argentina. Hoy es visto como barrera y problema en algunos contextos urbanos, ya que impide la circulación continua del medio automotor. Esa perspectiva puede considerarse conflictiva, pero el sistema ferroviario no debiera postularse como un impedimento para el desarrollo, sino que la cuestión está en cómo urbanizarlo y vincularlo nuevamente a la dinámica de las ciudades. El SIG integra y analiza información espacial, facilita el cruzamiento, superposición y enfrentamiento de capas para trabajar a varios niveles de detalle de manera jerárquica, tiene la agilidad de editar y adaptar datos propiciando flexibilidad en el proceso de planificación territorial.

Si bien nuestro abordaje a escala nacional y regional ha intentado lograr la reunión de datos hallados en distintas fuentes, junto a la elaboración manual de elementos digitales, creemos que aún queda mucho por hacerse en materia de ferrocarriles. Las ideas de accesibilidad, conectividad y movilidad penetran a una sociedad global en constante cambio y en busca de innovaciones para un desarrollo que demanda producción de conocimiento. Si bien pueden hallarse políticas públicas que intentan poner en valor al modelo de gestión ferroviaria, existe una distorsión entre las propuestas y el accionar concreto del Estado. Es en este punto donde podemos insertar nuestro aporte, ya que son indispensables los estudios previos, los diagnósticos y las bases de información para la producción de conocimiento científico y para el desarrollo de políticas públicas. 


\section{Q Bibliografía}

»Amores Carredano, F.J.d., García Sanjuán, L., Hurtado Pérez, V., Márquez Rosales, H. y Rodríguez-Bobada Gil, M.d.C. (1996). Una experiencia piloto de transferencia a soporte SIG del inventario de yacimientos arqueológicos de Andalucía. PH: Boletín del Instituto Andaluz del Patrimonio Histórico, 4 (15), 153161. Disponible en https://idus.us.es/xmlui/handle/11441/72799

» Ministerio de Fomento, Gobierno de España. Administración de Infraestructuras Ferroviaria. (s/f.). Diccionario de términos ferroviarios. Recuperado de: http:// prensa.adif.es/ade/uo8/GAP/Prensa.nsf/dicciona.htm (25/09/2018)

» Balsa Barreiro, J.y Brocal Ruíz, R. (s.f.). Los sistemas GMAOy SIG como herramientas para la gestión integrada en la administración local. Recuperado de: http://unpan1. un.org/intradoc/groups/public/documents/icap/unpan045022.pdf

"Borsotti, C. A. (2009). Temas de metodología de la investigación en ciencias sociales empíricas. Buenos Aires: Miño y Dávila.

"Buttler, K., A. (2012) Apliacaciones de los SIG en la Geografía Humana. En Sánchez Ayala, L. (comp.). Geografía Humana. Conceptos básicos y aplicaciones, Bogotá, Colombia: Ediciones Uniandes.

»Buzai, G. D., Baxendale, C. A., y Cruz, M. R. (2009). Fases de un proyecto de investigación en estudios de geografía aplicada basados en el uso de sistemas de información geográfica. Fronteras, 8(8), 31-40.

»Baxendale, Claudia; Buzai, Gustavo Daniel. (2013). Aportes del análisis geográfico con Sistemas de Información Geográfica como herramienta teórica, metodológica y tecnológica para la práctica del ordenamiento territorial. Persona y sociedad, 27(2), 113-141.

»Buzai, G., D. (2015) Conceptos fundamentales del análisis espacial que sustentan la investigación científica basada en geotecnologías. En: Fuenzalida, M., Buzai, G. D., Moreno Jiménez, A. y otros. (comp.) Geografía, geotecnología y análisis espacial: tendencias, métodos y aplicaciones. 1ra ed., Santiago de Chile: Editorial Triángulo.

"Buzai y Baxendale, C. (2006). Análisis socioespacial con sistemas de información geográfica, Buenos Aires, Argentina: Lugar Editorial.

»Campoles, V., Paloma, V. (2010). Sistema de Información Geográfica: Análisis evolutivo del fenómeno ferroviario en la ciudad de Rosario. Rosario: Universidad Nacional de Rosario. Recuperado de: https://docplayer.es/14379801-Sistemade-informacion-geografica-analisis-evolutivo-del-fenomeno-ferroviario-en-laciudad-de-rosario.html

"Castellano, D. (2010). Aplicación de los sistemas de información geográfica en el ordenamiento territorial. Ventana Informática (22), 39-53.

»Esri (2019). Crear mapas. Elegir mapa base. Recuperado de: https://doc.arcgis. com/es/arcgis-online/create-maps/choose-basemap.htm (19/11/2018)

" Gilavert Margalef, J., y Puig i Polo, C. (2008). Estudio comparativo de herramientas SIG Libres aplicadas a contextos de cooperación al desarrollo. En II Jornadas de SIG Libre, 1-13.

" Gómez Castaño, J. (2013). Tratamiento geoespacial del recorrido de trenes y de 
tramos ferroviarios: Mejoras en la interacción con la infraestructura. Jornadas Ibéricas de Infraestructuras de Datos Espaciales, Toledo. Recuperado de: https:// www.researchgate.net/publication/258498576_Tratamiento_geoespacial_del_ recorrido_de_trenes_y_de_tramos_ferroviarios_Mejoras_en_la_interaccion_ con_la_infraestructura

» GómezCastaño,J.(2012).INSPIRE: base delaimplementación de unainfraestructura de datos espaciales para la interoperabilidad de datos geográficos del ferrocarril en Europa. Recuperado de: https://www.researchgate.net/publication/232614028 INSPIRE_BASE_DE_LA_IMPLEMENTACION_DE_UNA_INFRAESTRUCTURA_ DE_DATOS_ESPACIALES_PARA_LA_INTEROPERABILIDAD_DE_DATOS_ GEOGRAFICOS_DEL_FERROCARRIL_EN_EUROPA

" Gómez Castaño, J. (2010). Desarrollo de una Infraestructura de Datos Espaciales Ferroviaria basada en Software Libre. Recuperado de: https://www. researchgate.net/publication/232607882_Desarrollo_de_una_Infraestructura_ de_Datos_Espaciales_Ferroviaria_basada_en_Software_Libre

» Gutiérrez Puebla J.y Gould, M. (1994). SIG: Sistemas de información geográfica. Madrid, España: Editorial Síntesis.

»Ferromapas. (s/f). Mapas ferroviarios electrónicos. Argentina: Ferromapas, mapas ferroviarios electrónicos. Recuperado de http://www.ferromapas.com.ar/ index.php (27/07/2018).

" Harvey, D. (1983). Teorías, leyes y modelos en geografía. Madrid: Alianza Editorial.

» Hidalgo, G., Rosas, J., \& Strabucchi, W. (2012). La representación cartográfica como producción de conocimiento: Reflexiones técnicas en torno a la construcción del plano de Santiago de 1910. ARQ (Santiago) (80), 62-75

"Luna, P. L., y Vergara, S. C. (2010). Sistema de Información Geográfica para la ayuda de toma de decisiones en políticas sociales. Centro de investigación y de estudios avanzados del instituto politécnico nacional, DF México.

» Michael R. M. MapCruzin. (1996). Download Free Argentina Country, Cities and Places GIS Shapefile Map Layers. Gran Bretaña: MapCruzin. Recuperado de https://mapcruzin.com/free-argentina-country-city-place-gis-shapefiles.htm (01/08/2018).

" Ministerio de Defensa, Presidencia de la Nación. Instituto Geográfico Nacional. (s/f). Capas SIG. Argentina: IGN. Recuperado de http://www.ign.gob.ar/ NuestrasActividades/InformacionGeoespacial/CapasSIG (28/07/2018).

" Ministerio de Transporte, Presidencia de la Nación. Trenes Argentinos Operaciones. (s/f). Trenes I Horarios, tarifas y recorridos. Argentina: Trenes Argentinos Operaciones. Recuperado de: www.argentina.gob.ar/transporte/ trenes-argentinos (12/08/2018).

" Miraglia, M., Caloni, N., \& Buzai, G. (2015). Sistemas de Información Geográfica en la investigación científica actual. Buenos Aires: Ediciones UNGS. Recuperado de https://www.ungs.edu.ar/wp-content/uploads/2018/03/668_SIG-Actual_ FINAL_web.pdf

»Olaya, (2012). Sistemas de información geográfica. Tomo I y II. Disponible en: http://volaya.github.io/libro-sig/

»Raposo, I. M. (2014). Una mirada actual al ferrocarril de cargas en la Argentina. Transporte y Territorio, (10), 33-57

"Rascovan, A. (2016). La infraestructura y la integración regional en América del Sur. Una visión geopolítica de los proyectos ferroviarios en el marco de IIRSA- 
COSIPLAN. Relaciones Internacionales, (31), 1-23.

»Sastre Olmos, P. (2010). Sistemas de Información Geográfica (SIG): Técnicas básicas para estudios de biodiversidad. Instituto Geológico y Minero de España.

»Satélite Ferroviario. (s/f). Bienvenido a MDSF - Mapa Definitivo de Satélite Ferroviario. Argentina: Satélite Ferroviario. Recuperado de https:// sateliteferroviario.com.ar/horarios/mapa_argentina.htm\#caba (20/07/2018).

»Schweitzer, M. (2014). Políticas ferroviarias en la argentina. Planes y proyectos en la primera década del siglo XXI. Transporte y Territorio, (10), 13-32.

»Solanas-Jimenez, J. (2018) Tratamiento de cartografía histórica para el análisis de la forma urbana en sistemas de información geográfica mediante SIG. Biblio $3 W, 23(1), 1-16$.

»Trenes Argentinos Cargas. (2016). Nuestra Red. Argentina: Trenes Argentinos Cargas. Recuperado de https://www.bcyl.com.ar/red (19/08/2018).

"Willems, P., \& Díaz Navarrete, G. (2002). Herramientas de SIG como soporte a la planificación territorial dentro del estudio de ordenamiento territorial de las laderas sur-orientales del volcán Pichincha en Quito, Ecuador, en X Congreso del Grupo de Métodos Cuantitativos, Sistemas de Información Geográfica y Teledetección. Ciencia y Tecnología de la Información Geográfica en un Mundo Globalizado. Universidad de Valladolid, Asociación de Geógrafos Españoles. Recuperado de: https://dialnet.unirioja.es/servlet/articulo?codigo $=4039164$

\section{María Alejandra Saus / produccioncientificaydocencia@gmail.com}

Doctora en Arquitectura (UNR). Arquitecta (UNL). Investigadora Asistente del CONICET. Docente en la Facultad de Arquitectura, Diseño y Urbanismo (FADU- UNL). Especialista en integración del ferrocarril en el medio urbano. Integra y dirige proyectos de investigación. Ha publicado numerosos artículos y ponencias sobre infraestructura ferroviaria. Ha trabajado en la Fundación de los Ferrocarriles Españoles (Madrid) y ha dictado seminarios sobre infraestructura y transporte.

\section{Julián Rolé / julian.rolez1@gmail.com}

Profesor en Geografía de la Facultad de Humanidades y Ciencias de la Universidad Nacional del Litoral y estudiante avanzado de la Licenciatura en Geografía de la misma institución. Ha realizado cursos en el área de manejo de Sistema de Información Geográfica; ha realizado una adscripción en docencia universitaria durante el cursado del profesorado en Geografía y una adscripción en investigación en el área de transporte e infraestructura, referido al Ferrocarril Belgrano en las últimas décadas.

\section{Andrés Ignacio Aguirre / andrewaguirre@outlook.com}

Estudiante avanzado de la Licenciatura y el Profesorado en Geografía de la Facultad de Humanidades y Ciencias de la Universidad Nacional del Litoral. Ha realizado diversos cursos en la temática SIG y teledetección en distintas instituciones. Actualmente se encuentra realizando una adscripción en investigación referida a la temática de la infraestructura ferroviaria y una Beca CIN titulada "Los espacios verdes públicos y su incidencia en la calidad de vida de la población de la localidad de Sunchales". 